\title{
PRODUTIVIDADE DO TRABALHO, SALÁRIOS REAIS E DESEMPREGO NA INDÚSTRIA DE TRANSFORMAÇÃO DO BRASIL NA DÉCADA DE 1990 TEORIA E EVIDÊNCIA*
}

\author{
Cíntia Rubim de Souza Netto ${ }^{* *}$
}

\section{Marcelo Luiz Curado ${ }^{* * *}$}

\begin{abstract}
RESUMO Este artigo investiga se os ganhos de produtividade do trabalho verificados na indústria de transformação brasileira nos anos 90 tiveram algum impacto sobre o comportamento dos salários reais. Para isso, utiliza o modelo de Ball e Moffit (2001), que incorpora a produtividade do trabalho à explicação da variação dos salários reais. A década de 1990 foi dividida em dois períodos para fins de análise: janeiro de 1990 a junho de 1994, e julho de 1994 a dezembro de 2000. Os resultados apontarão que a produtividade do trabalho foi uma variável significativa na explicação dos salários reais antes do Plano Real.
\end{abstract}

Palavras-chave: produtividade do trabalho; salários reais; indústria de transformação

Código JEL: E24

\section{LABOR PRODUCTIVITY, REAL WAGES AND UNEMPLOYMENT IN THE BRAZILIAN MANUFACTURING IN 90'S: THEORY AND EVIDENCE}

ABSTRACT This paper investigates if the gains of labor productivity verificated in the Brazilian industry in the nineties had some impact on the behavior of real wages. For this uses the Ball and Moffit's (2001) model, wich incorporates the labor

* Artigo recebido em 22 de março de 2004 e aprovado para publicação em 13 de julho de 2005.

** Doutoranda do Programa de Pós-graduação em Desenvolvimento Econômico da Universidade Federal do Paraná - UFPR, e-mail: cintiapr@terra.com.br

*** Professor adjunto do Departamento de Economia da Universidade Federal do Paraná - UFPR / Programa de Pós-graduação da Universidade Federal do Paraná (PPGE/UFPR), e-mail: mcurado@ufpr.br 
productivity in a explanation of the real wages variation. The nineties were divided in two periods for analysis: January 1990 to June 1994 and July to December 2000. The results will point out that the labor productivity was a significative variable in the explanation of wages before the Real Plan.

Key words: labor productivity; real wages; manufacturing 


\section{INTRODUÇÃO}

É sabido que a produtividade do trabalho da indústria aumentou sobremaneira no Brasil na década de 1990. Tal crescimento foi originado por uma conjugação de fatores dentre os quais salientam-se a abertura comercial, as privatizações e a estabilidade da moeda.

Analisando-se o salário real neste período, observa-se que o mesmo apresentou crescimento na primeira metade da década. Esse fato foi proporcionado, dentre outros fatores, pela valorização cambial, pela redução dos preços dos bens assalariados, das tarifas de importação e do emprego de menor qualificação.

Passados os impactos iniciais dos efeitos desses processos, o que se observou foi um crescimento negativo dos salários na segunda metade da década em torno de $-0,6 \%$ ao ano. Isso evidencia que, embora a produtividade do trabalho e os salários tenham sido crescentes na primeira fase do período, existiram fatores incidentes sobre essas variáveis que acabaram por distanciar suas trajetórias.

Dentre os modelos que analisam a determinação das variações de preços e salários, tem-se o trabalho de Phillips, que em 1958, em seu famoso texto intitulado The rellationship between unemployment and the rate of change of money wage rates. In the United Kingdom, 1861-1957, analisava a relação entre mudanças nos salários e desemprego. Outros pesquisadores encontraram relação inversa similar entre desemprego e inflação de preços, que ficou conhecida como "curva de Phillips".

Recentemente, outras variáveis passaram a incorporar os modelos de determinação do nível de preços e salários. Dentre elas, surge a versão que incorpora a produtividade do trabalho, de Ball e Moffit (2001). A inclusão desta variável numa curva de Phillips com expectativas teve representatividade na explicação dos salários para a economia norte-americana no período 1962-2000. Esses autores buscaram explicar que o diferencial de salário real (taxa de crescimento) pode ser explicado pela produtividade do trabalho, pelo desemprego e por um termo que chamaram de "aspirações para aumento de salário".

Isto posto, este trabalho pretende averiguar a possibilidade de se vislumbrar, na indústria de transformação brasileira dos anos 90, que relações apresentaram as variáveis produtividade do trabalho e salários reais e que 
impactos o crescimento da primeira pode ter tido sobre a segunda. Salientase que o objetivo aqui é analisar as relações entre as variáveis objeto de estudo e é nesse sentido que a adoção do modelo proposto por Ball e Moffit (2001) entra na discussão.

O artigo está estruturado da seguinte forma: a seção 1 trata da metodologia utilizada para a investigação proposta. A seção 2 apresenta a discussão dos salários sob o enfoque do modelo de Ball e Moffit (2001). A seção 3 descreve o comportamento das variáveis objeto de estudo para a indústria de transformação brasileira na década de 1990. A subseção 3.1 propõe, num exercício econométrico, a incorporação da variável produtividade do trabalho na explicação dos salários reais para a economia brasileira. E, fechando este artigo, a seção 4 resume as considerações finais.

\section{METODOLOGIA}

A fim de analisar as relações entre as variáveis produtividade do trabalho e salários reais, foram utilizados dados da Pesquisa Industrial Mensal - Produção Física e Dados Gerais (PIM-PF e PIM-DG), realizada pelo IBGE. No que se refere a esta fonte de dados, algumas considerações se fazem necessárias.

O IBGE trabalha com o conceito de produção física como uma proxy do valor agregado. Utilizar a produção física como proxy do valor agregado significa supor que a evolução da produção física e a do valor da produção real sejam a mesma e que a relação entre o valor de produção e o consumo intermediário se mantenha constante ao longo do tempo.

Outra limitação que aparece nessa fonte de dados refere-se à defasagem da base de ponderação do valor de transformação industrial. A Pesquisa Industrial Mensal - Produção Física tem como base o Censo Econômico de 1985. Já a Pesquisa Industrial Mensal - Dados Gerais está ainda mais defasada, pois tem sua base de ponderação no Censo Industrial de 1980. A PIMDG foi substituída pela Pesquisa Industrial Mensal de Emprego e Salário (PIMEs) em 2000, entretanto a utilização da primeira deve-se, sobretudo, ao objetivo de análise da década de 1990, uma vez que a PIMES apresenta dados das séries aqui analisadas a partir de dezembro de 2000.

Sendo assim, a PIM-PF e a PIM-DG, embora tenham "envelhecido" em razão das mudanças por que passou a economia brasileira nos últimos anos, 
são muito usadas para monitorar as tendências das variáveis investigadas. Entretanto, os resultados obtidos devem ser analisados levando em conta essas limitações (Sabóia e Carvalho, 1997).

Considerando-se essas informações, há duas formas de se calcular a produtividade do trabalho. A primeira é dividindo a produção física pelo pessoal ocupado na produção e a segunda é dividindo pelo número de horas

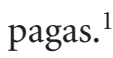

O cálculo da produtividade do trabalho tomado para o propósito deste artigo compreende o valor agregado dividido pelo número de horas pagas na produção. Optar-se-á por esta metodologia acreditando-se que a produtividade por hora é mais precisa que a produtividade por trabalhador, por incorporar a jornada de trabalho. Em outras palavras, a produção por trabalhador pode aumentar simplesmente porque esses estão trabalhando mais tempo, sem significar uma produção por hora maior. Esse indicador de produtividade traduzirá a produtividade média do trabalho, e será expresso por

$$
\theta=\frac{P F}{H P P}
$$

onde $\theta$ é a produtividade média do trabalho, $P F$ é a produção física e HPP são as horas pagas na produção.

O indicador de horas pagas capta horas não efetivamente trabalhadas, como férias, feriados, descanso remunerado, dentre outras. No que tange à questão da terceirização de atividades administrativas e de apoio, uma vez que este indicador refere-se a horas pagas na produção, ou seja, que dizem respeito direta ou indiretamente ao processo, o fenômeno desta terceirização não interfere, por definição, neste indicador, pois tais atividades nunca fizeram parte da sua base de dados (Almeida, 1999).

Transformando os valores-índices de produção física e horas pagas na produção em logaritmos naturais e subtraindo um pelo outro, obtêm-se os valores para a variável produtividade do trabalho utilizada neste trabalho. O salário é o salário contratual médio real que representa o salário contratual médio nominal deflacionado pelo IPA. Os dados referentes à taxa de desemprego foram extraídos do Instituto de Pesquisa Econômica Aplicada (IPEA), que utiliza os dados da Pesquisa Mensal de Emprego do IBGE. Refere-se à taxa de desemprego aberto (referência 30 dias), cuja base de cálculo 
contempla as regiões metropolitanas de Recife, Salvador, Belo Horizonte, Rio de Janeiro, São Paulo e Porto Alegre, bem como pessoas com 15 anos ou mais de idade.

Seguindo o modelo de Ball e Moffit (2001), o desemprego é incluído no modelo pela variável taxa de desemprego da economia, uma vez que esses autores buscaram estabelecer uma equação da curva de Phillips para a economia norte-americana.

As séries de produtividade média do trabalho e desemprego fora dessazonalizadas de forma que seus comportamentos de longo prazo fossem captados sem sofrer influência das variações sazonais. As séries dessazonalizadas são seguidas da sigla SA na análise gráfica. O método de ajustamento sazonal utilizado foi o processo multiplicativo das razões de médias móveis.

As séries tomadas para o exercício em questão são mensais, referentes ao período janeiro/1990 a dezembro/2000, perfazendo um total de 127 observações mensais. Conforme dito, optou-se por dividir o período em dois subperíodos distintos: o primeiro antecede o Plano Real e vai de janeiro de 1990 a junho de 1994 e o segundo período, pós-implantação do Plano, vai de julho de 1994 a dezembro de 2000. Com tal distinção de períodos buscou-se captar o comportamento das variáveis em estudo pós-abertura comercial no estágio sem estabilidade da moeda e, posteriormente, no período com estabilidade. O software utilizado para as estimações é o E-views.

\section{CURVA DE PHILLIPS: SALÁRIOS REAIS, DESEMPREGO \\ E PRODUTIVIDADE DO TRABALHO}

Ball e Moffit (2001) analisaram o fenômeno da "nova economia" dos Estados Unidos e, a partir disso, propuseram uma nova adaptação à curva de Phillips. O objetivo dos autores nesse trabalho foi o de mostrar que na economia americana, mudanças no crescimento da produtividade realmente afetam a curva de Phillips.

Esses autores derivaram um modelo para a curva de Phillips buscando explicar se o diferencial de salário real (taxa de crescimento) pode ser explicado pela produtividade do trabalho, pelo desemprego e por um termo que chamaram de "aspirações para aumento de salário" (que pode ser aproximado como um termo de expectativa). Tal modelo, basicamente, pode ser expresso por 


$$
(\omega-\pi)=\alpha-\gamma U+\delta \theta+(1-\delta) A+\eta
$$

onde $(\omega-\pi)$ é a taxa de crescimento do salário real, $U$ é a taxa de desemprego, $\theta$, a taxa de crescimento da produtividade do trabalho, $A$, o termo "aspiração" para aumento de salário, $\eta$, o erro e $\alpha, \gamma, \delta$ são parâmetros do modelo.

Completando o modelo acima, Ball e Moffit (2001) propõem a seguinte equação para inflação:

$$
\pi=\omega-\theta+v
$$

onde $v$ é outro erro.

A inflação de preços depende, portanto, do custo por unidade de trabalho $(\omega)$, que é a inflação salarial menos o crescimento da produtividade do trabalho $(\theta)$.

Substituindo (9) em (10), tem-se a curva de Phillips para inflação de preços:

$$
\pi=\alpha+\pi_{-1}-\gamma U-(1-\delta)(\theta-A)+\varepsilon
$$

onde $\varepsilon=\eta+v$.

No que se refere às "aspirações salariais", o termo $A$ da equação, este depende da média dos aumentos salariais passados percebidos pelos trabalhadores, ou seja, os autores estimaram $A$ regredindo o termo em:

$$
A=\beta A_{-1}+(1-\beta)(\omega-\pi)_{-1}
$$

onde $\beta$ é o coeficiente das "aspirações salariais" do período anterior e $(\omega-\pi)_{-1}$ é a taxa de crescimento do salário real no período anterior.

Substituindo a equação (11) nas equações (8) e (10), tem-se a curva de Phillips - inflação de salários (equação 12) e de preços (equação 13), respectivamente, considerando a produtividade do trabalho e as "aspirações" por aumentos salariais:

$$
\begin{aligned}
& (\omega-\pi)=\alpha-\gamma U+\delta \theta+(1-\delta)\left[\beta A_{-1}+(1-\beta)(\omega-\pi)_{-1}\right]+\eta \\
& \pi=\alpha+\pi_{-1}-\gamma U-\left\{(1-\gamma)\left[\theta-\left(\beta A_{-1}+(1-\beta)(\omega-\pi)_{-1}\right)\right]\right\}+\varepsilon
\end{aligned}
$$

Segundo os autores, para $\delta=1$, o crescimento da produtividade tem efeito positivo na inflação salarial e negativo na inflação de preços (equações 12 e 13). Então essa hipótese estritamente neoclássica parece indicar que o crescimento da produtividade não importa na curva de Phillips para 
inflação salarial. O crescimento da produtividade será ainda irrelevante no estado estacionário, onde $\theta=A$. Na opinião dos autores, isso explica por que pesquisas sobre a curva de Phillips costumam não enfatizar o crescimento da produtividade.

Entretanto, o crescimento da produtividade terá importância se o crescimento dos salários estiver em parte vinculado ao crescimento dos salários no passado, isto é, se $\delta<1$ (novamente equações 12 e 13).

\section{DÉCADA DE 1990 NO BRASIL: SALÁRIOS REAIS, DESEMPREGO E PRODUTIVIDADE DO TRABALHO NA INDÚSTRIA}

A economia brasileira ingressa nos anos 90 num cenário de abertura da economia e reestruturação produtiva. A abertura da economia, caracterizada por menores tarifas nominais e menores taxas de proteção efetiva, exerceu um efeito positivo sobre o aumento da produtividade. A redução nos preços dos bens de consumo assalariado elevou o salário real, ampliando o mercado para outros bens (Barros e Goldstein, 1997).

Assim, o processo de estabilização da economia com o Plano Real em 1994 somou-se ao que se designou de "novo modelo de inserção da economia brasileira”. Este novo modelo contemplava uma série de indicações e estratégias para a política industrial e de comércio exterior, dentre elas a exposição da indústria à competição internacional, visando a uma maior inserção no mercado externo e à melhoria de qualidade e preço no mercado interno, ao aumento da competição em setores oligopolizados e à capacitação tecnológica da empresa nacional.

A conseqüência dessa mudança foi a alteração profunda nos condicionantes fundamentais do ambiente econômico, induzindo a uma grande reorganização dos mercados, o que provocou uma mudança de mentalidade e de estratégia das empresas, induzindo-as à preocupação com a aquisição de capacitação tecnológica e com a busca de eficiência produtiva.

Neste novo contexto, uma mudança de fundamental importância estava se dando na economia brasileira. Tal mudança pode ser referida como a intensificação do componente endógeno da pressão competitiva. Em outras palavras, a abertura comercial levou as empresas, principalmente aquelas que já tinham pouca expressão no mercado externo antes das mudanças, a um movimento concorrencial interno bastante expressivo (Castro, 1999). 
Coutinho (1997) apontava para um processo "virtuoso" de reestruturação industrial aquele que, dentre outros fatores, fosse capaz de produzir ganhos de produtividade significativos e persistentes, suficientes para neutralizar os efeitos da apreciação da taxa de câmbio pós-Real e estimular uma significativa reação das exportações.

No que se refere aos ganhos de produtividade do trabalho, houve um aumento expressivo na década de 1990. Segundo Sabóia e Carvalho (1997), a taxa média geométrica de crescimento da produtividade do trabalho nos anos 90 foi de $7 \% .^{2}$

No âmbito da discussão do fenômeno de crescimento da produtividade do trabalho na década de 1990, as abordagens divergiram no tocante à causa desse crescimento. Para alguns, como Bonelli e Fonseca (1998) e Feijó e Carvalho (1994), tal crescimento se deveu a mudanças estruturais ocasionadas pelas transformações que a economia brasileira sofreu a partir do final dos anos 80 e início dos anos 90. Dentre esses fatores, os autores apontam a abertura comercial, responsável por alterações estruturais nas empresas, originando o "novo paradigma tecnológico-gerencial".

Outros autores, no entanto, acreditavam que o crescimento da produtividade seria fruto das flutuações cíclicas da economia e não do processo de reestruturação produtiva. Desta vertente fazem parte os trabalhos de Considera (1995) e Silva et al. (1993). Para esses autores, o aumento da produtividade decorreu da recessão do início dos anos 90, com a expressiva queda do Produto, e eles não concordavam que teria havido mudanças estruturais tecnológicas na economia, o que só seria possível com mais investimento. Sendo assim, os ganhos de produtividade seriam temporários e oriundos de situações transitórias na economia brasileira. O que se verificou foi o declínio das taxas de investimento e o fechamento de empresas menos produtivas, o que contribuiria, nessa visão, para o aumento da produtividade.

A comparação internacional mostrou que taxas anuais de crescimento da produtividade do trabalho da ordem de $7 \%$ ao ano ou mais ocorreram em algumas economias por longos períodos, especialmente as asiáticas. Isso mostra que, por um lado, o fenômeno verificado no Brasil pode ser menos excepcional do que sugerem alguns especialistas. Por outro lado, o fôlego para a continuidade do crescimento da produtividade pode ser mais do que um fenômeno temporário (Sabóia e Carvalho, 1997). 
Nos anos 80 , por exemplo, a China apresentou uma taxa de crescimento da produtividade de $9,3 \%$, a Coréia de $8,4 \%$, a Índia de 7,8\%, a Indonésia de 7,5\%, a Colômbia de 5,3\% e, no período 1990-1995, o México apresentou uma taxa de $6 \%$ e a Argentina, de 4,8\%. Portanto, o aumento da produtividade do trabalho na indústria brasileira não parece nada absurdo quando comparado a outros países (Carvalho, 2000).

Franco (1998) apontava que a manutenção de altas taxas de crescimento da produtividade representaria uma extraordinária novidade no tocante às características básicas do crescimento econômico brasileiro. Dentre os fatores que proporcionariam tal evento está a afirmação de que os ganhos de produtividade induziriam a conseqüências redistributivas, pois para esse autor parte do crescimento de produtividade seria apropriada pelos salários.

Como para Franco (1998), esse crescimento da produtividade é defendido como de crucial importância também por Bonelli e Fonseca (1998) que afirmam ser somente a partir desses ganhos possível obter-se simultaneamente crescimento dos salários e aumento da competitividade das empresas. Esses autores salientam que foi a partir de ganhos expressivos na produtividade, acompanhados de aumentos de salários, que se desenvolveram os principais mercados de massa no mundo.

Nesta visão, os ganhos de produtividade ajudariam a explicar os ganhos salariais observados na indústria recentemente. Com o aumento da produtividade, os autores salientam que é de se esperar que os aumentos de salários reflitam os de produtividade. Um indicador que na visão deles permite analisar este aspecto é o que está sendo utilizado neste trabalho, qual seja, o valor da produção dividido pelo número de horas pagas.

O gráfico 1 mostra a evolução da produtividade do trabalho e dos salários reais (deflacionado pelo IPC) na década de 1990. Conforme pode-se observar no fato de os ganhos salariais estarem refletindo os ganhos de produtividade, há uma forte associação entre as séries salários reais e a produtividade do trabalho na primeira metade da década, passando essas variáveis a assumir trajetórias distintas após esse período. Entretanto, os salários reais apresentam-se com tendência de crescimento até 1999.

A economia brasileira iniciou a década de 1990 com uma forte recessão. Após um período de elevadas taxas de inflação no final dos anos 80, no iní- 


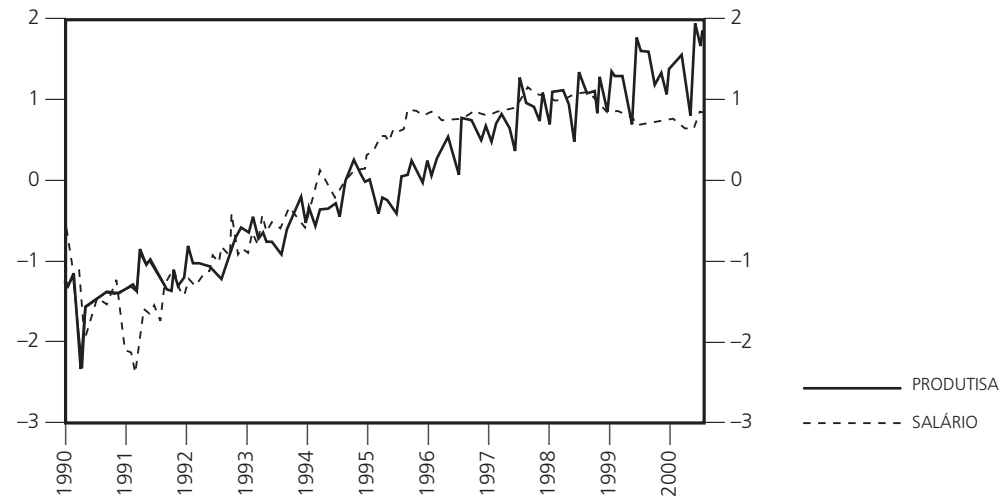

Fonte: PIM-DG e PIM-PF/BBGE.

cio de 1990 a moratória da dívida interna implementada pelo governo teve um efeito fortemente recessivo. A taxa de desemprego aberto, que em março de 1990 era de 4\% da força de trabalho, atingiu 6\% no segundo semestre de 1992.

Para Camargo, Neri e Reis (1999), esse movimento das taxas de desemprego sugeria um elevado grau de flexibilidade do mercado de trabalho brasileiro em relação aos choques vividos pela economia. Já durante a década de 1990, a taxa de desemprego apresenta uma tendência de crescimento que não está associada diretamente aos movimentos cíclicos do produto. O gráfico 2 ilustra o comportamento da produção e do desemprego nos anos 90.

É fato que, ao contrário do que preconizaram os adeptos da tese de que os ganhos de produtividade seriam advindos de flutuações do emprego e, portanto, não se caracterizariam como estruturais, o que se verificou foi que a produtividade continuou durante toda a década de 1990 com forte tendência ao crescimento, mesmo com a recuperação da atividade econômica no período pós-Plano Real (Rossi Jr. e Ferreira, 1999).

Assim, dentre os fatores que originaram os ganhos de produtividade da década de 1990, teve-se a conjugação dos aspectos macro já apontados e micro, oriundos da própria exposição das empresas à concorrência internacional, que as obrigou a empreender vigorosos programas de modernização tecnológica e especialização, e, por conseguinte, produtos com qualidade e preços mais competitivos. 
Gráfico 2: Produção física e desemprego nos anos 90

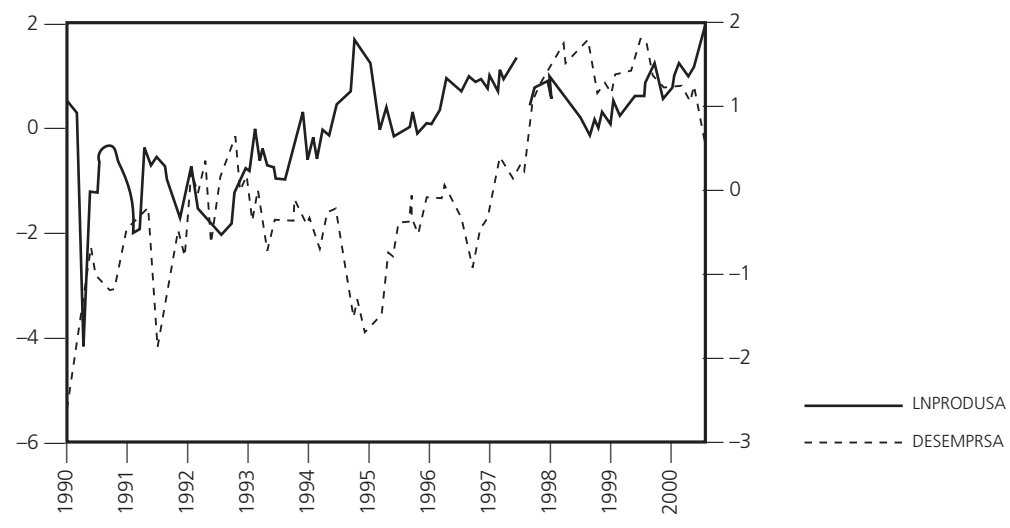

Fonte: PIM-DG e PIM-PF/IBGE.

Gráfico 3: Produtividade do trabalho, salários e desemprego na década de 1990

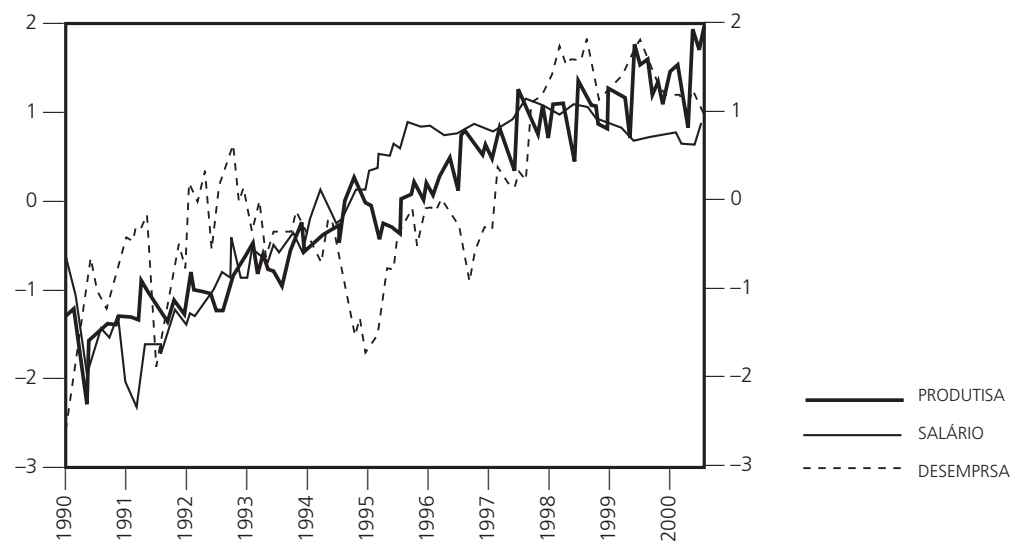

Fonte: PIM-DG e PIM-PF/IBGE.

Na década de 1990 podem-se distinguir pelo menos dois períodos, os quais serão tomados em separados neste trabalho. O primeiro período antecede o Plano Real e vai de janeiro de 1990 a junho de 1994; o segundo período refere-se à segunda metade da década, de julho de 1994 a dezembro de 2000. O gráfico 3 traz a evolução das variáveis produtividade do trabalho, salários reais e desemprego na década de 1990.

Na primeira metade da década observam-se dois comportamentos distintos da variável produtividade do trabalho. Pode-se definir um primeiro período que compreende o ano de 1990 até 1992, no qual as principais cau- 
sas da criação de um ambiente adverso foram o acirramento da concorrência provocado pela abertura da economia e a eclosão da recessão ocasionada pela política de estabilização macroeconômica. As empresas responderam com programas de racionalização de custos e a busca de eficiência com o intuito de defender seus mercados. O reflexo deste processo foi a redução concomitante do nível de produção e de emprego.

No primeiro período analisado, a produtividade do trabalho e os salários cresceram a uma taxa de aproximadamente $7,5 \%$ e 6,2\% ao ano, em média. Houve queda das horas pagas na produção (4,7\% ao ano, aproximadamente) e a produção física cresceu em torno de $1,2 \%$ ao ano.

A forte recessão que marcou o início deste período permite observar que o comportamento das horas pagas na produção acompanhou o comportamento da produção. No início deste período, a produtividade despenca por causa da recessão, que implicou uma queda mais acentuada da produção do que do número de horas pagas, mas a partir de 1993 há recuperação da produção, enquanto o número de horas pagas mostra uma certa estagnação. Vale notar que do começo de 1993 a meados de 1994, o traçado da curva de horas pagas não mostra uma redução muito grande.

O comportamento da produtividade parece, então, ser reflexo, neste período, mais da redução das horas pagas na produção industrial do que propriamente da produção. Embora a produção tenha apresentado uma queda expressiva no início do ano de 1990, houve recuperação da atividade econômica a partir de 1993.

Na segunda metade da década, mais precisamente no período que vai de julho de 1994 a dezembro de 2000, a produtividade do trabalho dispara, crescendo a uma taxa de $8 \%$ ao ano, enquanto a produção física cresce aproximadamente a uma taxa de $0,5 \%$ ao ano e as horas pagas despencam em torno de $5 \%$ ao ano. Os salários reais apresentam crescimento negativo de aproximadamente $-0,6$ ao ano, em média.

Desta forma, parece que o salto nos ganhos de produtividade do trabalho da segunda metade da década de 1990 foi, de fato, acompanhado por redução do emprego na indústria e crescimento levemente negativo nos salários. Esta redução do emprego no setor industrial, advinda das estratégias modernizadoras adotadas pela indústria, foi acompanhada por crescimento do pessoal ocupado no setor informal da economia. 
Houve uma acentuada tendência de elevação na taxa de desemprego durante o ano de 1995 e no início de 1996, após um período de queda imediatamente posterior à implementação do Plano Real. Por outro lado, a capacidade de absorção de mão-de-obra no setor industrial diminuiu consideravelmente - havendo inclusive redução dos postos de trabalho - em função do processo de abertura comercial (Ramos e Reis, 1997). Na visão desses autores, a tônica da política econômica dos anos 90 privilegiou ajustes que gerassem ganhos de produtividade para aumentar a competitividade da economia brasileira no cenário internacional.

Bonelli (1999) salienta que este processo de crescimento da produtividade representa uma ruptura com a experiência histórica, refletindo uma autêntica revolução tecnológico-organizacional (incluindo a substituição de mão-de-obra por capital). Nessa década, então, os ganhos de produtividade seriam explicados em parte pelo progresso técnico.

Esse autor defende que a elevação dos salários médios na primeira metade da década originou-se dos novos investimentos. Estes, ao proporcionarem uma distinção na demanda por mão-de-obra mais qualificada, permitiram aos trabalhadores mais qualificados aumentos nos salários. Ao mesmo tempo, a dispensa de trabalhadores neste período atingia postos de menor remuneração.

Parece, então, que nesta fase os aumentos salariais refletiram os ganhos de produtividade da mão-de-obra induzidos pelo uso de novos equipamentos, apesar da queda no nível de emprego (que, a priori, reduziria os salários). Neste período, na visão desse autor, a elevação da produtividade foi de fato acompanhada pela elevação dos salários. Conforme o modelo econométrico proposto na subseção seguinte, de fato a produtividade do trabalho se mostrará significativa para a explicação dos salários nesse primeiro período.

\subsection{Incorporando a produtividade do trabalho na explicação dos}

salários reais para a economia brasileira: um exercício econométrico

Esta subseção pretende evidenciar se a taxa de crescimento dos salários reais da indústria de transformação na década de 1990 pode ser explicada pela produtividade do trabalho e pelo desemprego. Para tanto, parte-se do modelo teórico adaptado da curva de Phillips apresentado por Ball e Moffit (2001), com ressalvas para a economia brasileira. ${ }^{3}$ 
Salienta-se que para o exercício em questão, a ser aplicado para o caso da economia brasileira na década de 1990 , supõe-se $\beta=0$ (equação 11), evidenciando que os trabalhadores "aspiram" a manter a taxa de crescimento do salário real do período anterior.

As séries produtividade do trabalho, salário real e desemprego no período de janeiro de 1990 a junho de 1994 apresentaram-se estacionárias em primeira diferença no primeiro período, I(1) (tabelas A1, A2 e A3 do Anexo).

No que se refere ao período de julho de 1994 a dezembro de 2000, as séries salários reais e produtividade do trabalho mostraram-se estacionárias em primeira diferença, I(1). Já o desemprego mostrou-se estacionário em segunda diferença apenas, I(2). As tabelas dos testes encontram-se em anexo. O número de defasagens do teste Dickey-Fuller Aumentado (DFA) escolhido foi de 4 lags em cada série.

Sendo assim, dada a diferença na ordem de integração entre as variáveis no segundo período, esta seção contemplará a tentativa de aplicação do modelo apenas para o primeiro período. Antes disso, algumas relações entre as variáveis produtividade do trabalho e desemprego serão observadas para os dois períodos, como o teste de causalidade de Granger e o teste de co-integração de Johansen.

A análise da co-integração entre duas variáveis é utilizada para verificar se existe uma relação linear de longo prazo entre duas variáveis. Isto posto, nesta subseção testa-se a co-integração entre salários reais e produtividade do trabalho. Em ambos os períodos, a co-integração foi testada pela aplicação do teste Johansen para co-integração e os resultados foram negativos para a existência de co-integração entre salários e produtividade do trabalho.

A hipótese nula do teste de que as variáveis não co-integram não pode ser rejeitada (tabelas A7 e A8 do Anexo). Como produtividade do trabalho e salários reais são séries I(1) em toda a década de 1990, o teste de Johansen também foi realizado para o total do período e os resultados, novamente, apontaram para a não-co-integração entre as variáveis. Desta vez, a probabilidade de se aceitar a hipótese nula de não-co-integração foi muito pequena. $^{4}$

O teste utilizado para verificar a causalidade entre a produtividade do trabalho e os salários reais da indústria de transformação brasileira foi o teste de Granger. Este testou, simultaneamente, se a "produtividade do traba- 
lho não causou salários" e se "salários não causaram produtividade do trabalho" em cada subperíodo e no total da década.

O resultado do teste concluiu que em todas as situações (primeira e segunda metades da década e no período como um todo), a hipótese nula de que "produtividade não causa salários" não pode ser rejeitada (tabelas A10, A11 e A12 do Anexo). Por outro lado, a hipótese de que salários não causam produtividade do trabalho é rejeitada, indicando que ao crescimento da produtividade do trabalho precedeu a elevação dos salários reais.

Feitas essas considerações, parte-se para o modelo econométrico, baseado, como já apontado, no modelo teórico adaptado da curva de Phillips apresentado por Ball e Moffit (2001). O modelo estimado contemplou o período de janeiro de 1990 a junho de 1994, com as variáveis em primeira diferença. As séries foram transformadas em logaritmos naturais. O método utilizado foi o de mínimos quadrados. A equação de regressão foi a seguinte:

$$
\Delta \ln (\omega-\pi)=\alpha+\Delta \ln (\omega-\pi)_{-1}-\gamma \Delta \ln U+\delta \Delta \ln \theta+\eta
$$

Os resultados estão sintetizados na tabela 1 .

Conforme os resultados foram significativos para a explicação dos salários reais no período de janeiro de 1990 a junho de 1994, verificam-se as variáveis salário real do período anterior $(p=0,0000)$ e produtividade do trabalho ( $p=0,0133)$. Já o desemprego não se mostrou significativo neste período $(p=0,2712)$. O poder explicativo do modelo, representado pelo coeficiente de determinação $R^{2}$, é alto (86\%).

Tabela 1: Resultados da regressão

MQONariável dependente d(sal)

Amostra ajustada (1990:01 1994:07)

Observações incluídas: 52 após ajustamentos

\begin{tabular}{lcccc}
\hline Variável & Coeficiente & Desvio-padrão & Estatística $t$ & Prob. \\
\hline$\alpha$ & 0,150624 & 0,251025 & 0,600035 & 0,5513 \\
\hline$(\omega-\pi)_{-1}$ & 0,967247 & 0,055660 & 17,37772 & 0,0000 \\
\hline$U$ & $-0,129042$ & 0,115923 & $-1,13170$ & 0,2712 \\
\hline$\theta$ & 0,228380 & 0,088821 & 2,571230 & 0,0133 \\
\hline$R^{2}$ & 0,864580 & Média da variável dependente & & 4,510953 \\
\hline$R^{2}$ ajustado & 0,856116 & D.P da variável dependente & \\
\hline E.P da regressão & 0,038754 & Critério de Akaike & & $-3,589386$ \\
\hline Soma (resid) ${ }^{2}$ & 0,072088 & Critério de Schwarz & $-3,439290$ \\
\hline Log. max. verossim. & 97,32404 & Estatística F & 102,1505 \\
\hline Durbin-Watson & 2,308005 & Probabilidade (estatística F) & & 0,000000 \\
\hline
\end{tabular}

Obs: Estimativas feitas pelos autores. 
Já ao se estimar a equação aceitando-se alguma defasagem para a taxa de desemprego, observa-se que os resultados não mudaram significativamente. Em outras palavras, a regressão da equação abaixo (com a variável taxa de desemprego defasada em dois períodos) continua assinalando para a significância do salário real defasado em um período e da produtividade do trabalho, evidenciando que para a economia brasileira a variável desemprego não explica variação de salário real. Ball e Moffit (2001) afirmam que a inclusão de defasagens para o desemprego não se mostrou significativa para a economia norte-americana.

$$
\Delta \ln (\omega-\pi)=\alpha+\Delta \ln (\omega-\pi)_{-1}-\gamma \Delta \ln U_{-1}-\chi \Delta \ln U_{-2}+\delta \Delta \ln \theta+\eta
$$

Os resultados desta nova regressão estão apontados na tabela 2.

Observando-se a tabela 2, verifica-se que o salário real defasado em um período e a produtividade do trabalho continuam significativas ( $p=0,0000$ e $p=0,0147$, respectivamente), enquanto o desemprego defasado não se mostrou significativo para a explicação dos salários reais neste período ( $p=$ 0,4401 e $p=0,6722$, respectivamente). O poder explicativo do modelo não se alterou significativamente, permanecendo em torno de $86 \%$. Esta regressão também não apresentou problema de heteroscedasticidade, uma vez que a probabilidade de se aceitar a hipótese nula de que os erros são homoscedásticos é de $p=0,284914$.

Tabela 2: Resultados da regressão (2)

MQONariável dependente d(sal)

Amostra ajustada (1990:01 1994:07)

Observações incluídas: 52 após ajustamentos

\begin{tabular}{lcccc}
\hline Variável & Coeficiente & Desvio-padrão & Estatística $t$ & Prob. \\
\hline$\alpha$ & 0,173937 & 0,261967 & 0,663965 & 0,5100 \\
\hline$(\omega-\pi)_{-1}$ & 0,962006 & 0,058060 & 16,56918 & 0,0000 \\
\hline$U_{-1}$ & $-0,093310$ & 0,119820 & $-0,778747$ & 0,4401 \\
\hline$U_{-2}$ & $-0,051089$ & 0,119962 & $-0,425881$ & 0,6722 \\
\hline$\theta$ & 0,238666 & 0,094141 & 2,535205 & 0,0147 \\
\hline$R^{2}$ & 0,863865 & Média da variável dependente & & 4,510974 \\
\hline$R^{2}$ ajustado & 0,852028 & D.P da variável dependente & & 0,103182 \\
\hline E.P da regressão & 0,039691 & Critério de Akaike & $-3,522478$ \\
\hline Soma (resid. $)^{2}$ & 0,072468 & Critério de Schwarz & $-3,333083$ \\
\hline Log. max. verossim. & 94,82319 & Estatística F & 72,97519 \\
\hline Durbin-Watson & 2,067161 & Probabilidade (estatística F) & & 0,000000 \\
\hline
\end{tabular}

Obs.: Estimativas feitas pelos autores. 
O modelo não apresentou problema de autocorrelação nos resíduos, ${ }^{5}$ embora tenha apresentado heteroscedasticidade.

O teste realizado para verificar a presença ou não de heteroscedasticidade foi o teste White (cross terms). A hipótese nula deste teste é a de que os erros são homoscedásticos, isto é, apresentam variância constante. A probabilidade de se aceitar esta hipótese foi muito baixa $(p=0,0003)$, o que denota que o modelo apresentou problema de heteroscedasticidade.

Segundo Gujarati (2000: 354) "heteroscedasticidade nunca foi um motivo para rejeitar um modelo que de outro modo seria bom. Mas tampouco ela deve ser ignorada". Muitas vezes, o que parece heteroscedasticidade pode decorrer do fato de que algumas variáveis importantes tenham sido omitidas do modelo.

Isto posto, o exercício econométrico aqui aplicado aponta que embora produtividade do trabalho e salários não tenham apresentado uma relação de equilíbrio de longo prazo e embora o aumento da produtividade do trabalho não "tenha causado" aumento nos salários, a produtividade do trabalho foi significativa para a explicação dos salários no período de janeiro de 1990 a junho de 1994. A análise de regressão lida com a dependência de uma variável em relação a outras, e isso não necessariamente implica causação.

\section{CONSIDERAÇÕES FINAIS}

A indústria de transformação brasileira da década de 1990 apresentou um comportamento crescente nas variáveis produtividade do trabalho e salários reais. A produtividade do trabalho cresceu, em parte, em função das transformações pelas quais a economia brasileira passou, dentre elas a abertura comercial, que impôs às empresas um novo cenário de competitividade.

Os salários reais do começo da década estavam referenciados a índices de preços, e com a estabilização da moeda incluindo a valorização cambial, a redução dos preços dos bens assalariados e a redução das tarifas de importação, pode-se sugerir que havia, por assim dizer, uma combinação de fatores influenciando a taxa de crescimento dos salários reais na década de 1990.

Embora a produtividade do trabalho e os salários tenham sido "aparentemente” convergentes na primeira fase do período, existiram fatores inci- 
dentes sobre essas variáveis que acabaram por distanciar suas trajetórias na segunda metade da década. Do lado da produtividade do trabalho, salientase que os esforços para a redução do custo da mão-de-obra, as tecnologias poupadoras de mão-de-obra e a conseqüente redução do emprego favoreceram seu desempenho crescente.

Do lado dos salários, parte pode ser explicada pela terceirização de muitas atividades, o que acabou transferindo massa salarial da indústria para os serviços e, conseqüentemente, deslocou o espaço para aumento nos salários das atividades do setor industrial para as do setor de serviços, e, também, pela redução do emprego.

A década de 1990 foi dividida em dois períodos para as investigações empíricas: janeiro de 1990 a junho de 1994, antes do Plano Real, e julho de 1994 a dezembro de 2000, pós-Plano Real. Antes do Plano Real, como já mencionado, a produtividade do trabalho e os salários reais parecem ter apresentado a mesma tendência de crescimento; entretanto, a partir de 1994 e já nos primeiros meses após o Plano, até aproximadamente o final de 1997, os salários reais cresceram acima da produtividade, em parte, graças à recuperação do poder de compra dos trabalhadores pelos fatores já expostos. Já mais para o final da década, os salários passaram a apresentar taxas de crescimento negativas, enquanto a produtividade do trabalho seguiu crescendo a taxas positivas.

Também a redução do número de horas pagas na produção da indústria de transformação observada na década de 1990 levou, por um lado, a uma redução nos salários reais pagos neste setor e, por outro, pelo cálculo do indicador da produtividade adotado neste trabalho (produção física dividida pelo número de horas pagas), a um aumento na produtividade do trabalho. Nesse cenário, essas duas variáveis apresentaram direções opostas.

Isto posto, a conjugação de fatores como os citados acima incidiu sobre as variáveis produtividade do trabalho e salários reais. Na tentativa de elucidar as relações entre essas variáveis, três investigações de natureza quantitativa foram realizadas neste trabalho: a análise de co-integração, o teste de causalidade e a tentativa de aplicação do modelo de Ball e Moffit (2001) para a economia brasileira no que se refere à incorporação da variável produtividade do trabalho na explicação dos salários reais. As diferenças observadas nas séries permitiram que a análise de regressão fosse realizada apenas 
para o primeiro período, no qual as séries investigadas apresentaram-se todas I(1). No segundo período, não foi possível obter uma análise de regressão do tipo proposto, dadas as diferenças nas ordens de integração entre salários reais e produtividade do trabalho, I(1), e desemprego, I(2).

Enquanto a teoria econômica tradicional sugere que os movimentos entre as variáveis possam ocorrer no mesmo sentido e magnitude, a análise dos dados permitiu identificar que, em muito por causa das especificidades de mercados não perfeitamente concorrenciais e do cenário no qual esse crescimento da produtividade se deu, este movimento de convergência não ocorreu ao longo do período estudado. Em termos econométricos, as variáveis produtividade do trabalho e salários reais não co-integraram, ou seja, não apresentaram uma relação de equilíbrio de longo prazo.

Também não se verificou um movimento de "causação" no sentido produtividade do trabalho para salários, mas sim o oposto, ou seja, parece que o aumento no salário real (mesmo que, como observado, esse aumento tenha sido inferior ao da produtividade do trabalho) foi um fator que também proporcionou a elevação da produtividade do trabalhador desta indústria, à la teoria do salário-eficiência.

Entretanto, a análise de regressão permitiu observar que a variável produtividade do trabalho foi significativa e de sinal positivo para a explicação dos salários reais no primeiro período analisado. Isto pode ocorrer porque, conforme a teoria, a análise de regressão lida com a dependência de uma variável em relação a outra, o que não implica necessariamente causação. Neste exercício, também foi significativa a variável salário real defasado; já o desemprego não mostrou-se significativo.

Se, por um lado, produtividade do trabalho e salários reais não apresentaram relação de equilíbrio de longo prazo, por outro, a produtividade do trabalho foi significativa para a determinação dos salários reais no primeiro período estudado. No que se refere a essas diferenças, salienta-se, novamente, que a inclusão de períodos mais longos pode se traduzir num resultado de longo prazo diferente, enquanto defende-se que a significância da produtividade do trabalho nos salários na primeira fase do período pode ser justificada pelo seu crescimento peculiar, ou seja, os ganhos de produtividade podem ter sido em parte apropriados pelos salários, outra parte pelos lucros ou reinvestidos na própria indústria, como de fato foi defendido por uma linha de discussão acadêmica neste período no Brasil. 


\section{ANEXO}

Tabela A1: Teste de Dickey Fuller aumentado para salários reais (1990-1994) (variável em primeira diferença)

\begin{tabular}{|c|c|c|c|}
\hline Estatística do teste & $-4,379230$ & Valor crítico a $1 \%$ * & $-4,1584$ \\
\hline & & Valor crítico a $5 \%$ & $-3,5045$ \\
\hline & & Valor crítico a $10 \%$ & $-3,1816$ \\
\hline
\end{tabular}

*Valores críticos de MacKinnon para a rejeição da hipótese de raiz unitária.

Tabela A2: Teste de Dickey Fuller aumentado para produtividade do trabalho (1990-1994) (variável em primeira diferença)

\begin{tabular}{|c|c|c|c|}
\hline Estatística do teste & $-4,855848$ & Valor crítico a $1 \%$ * & $-4,1630$ \\
\hline & & Valor crítico a $5 \%$ & $-3,5066$ \\
\hline & & Valor crítico a $10 \%$ & $-3,1828$ \\
\hline
\end{tabular}

*Valores críticos de MacKinnon para a rejeição da hipótese nula.

Tabela A3: Teste de Dickey Fuller aumentado para desemprego (1990-1994) (variável em primeira diferença)

\begin{tabular}{|c|c|c|c|}
\hline Estatística do teste & $-4,317509$ & Valor crítico a $1 \%$ * & $-4,1584$ \\
\hline & & Valor crítico a $5 \%$ & $-3,5045$ \\
\hline & & Valor crítico a $10 \%$ & $-3,1816$ \\
\hline
\end{tabular}

*Valores críticos de MacKinnon para a rejeição da hipótese de raiz unitária.

Tabela A4: Teste de Dickey Fuller aumentado para salário (1994-2000) (variável em primeira diferença)

\begin{tabular}{|c|c|c|c|}
\hline Estatística do teste & $-4,223448$ & Valor crítico a $1 \%$ * & $-4,0853$ \\
\hline & & Valor crítico a $5 \%$ & $-3,4704$ \\
\hline & & Valor crítico a $10 \%$ & $-3,1620$ \\
\hline
\end{tabular}

*Valores críticos de MacKinnon para a rejeição da hipótese de raiz unitária.

Tabela A5: Teste de Dickey Fuller aumentado para produtividade do trabalho (1994-2000) (variável em primeira diferença)

\begin{tabular}{|c|c|c|c|}
\hline Estatística do teste & $-5,010067$ & Valor crítico a $1 \%$ * & $-4,0890$ \\
\hline & & Valor crítico a $5 \%$ & $-3,4721$ \\
\hline & & Valor crítico a $10 \%$ & $-3,1629$ \\
\hline
\end{tabular}

*Valores críticos de MacKinnon para a rejeição da hipótese de raiz unitária.

Tabela A6: Teste de Dickey Fuller aumentado para desemprego (1994-2000)

(variável em segunda diferença)

\begin{tabular}{|c|c|c|c|}
\hline Estatística do teste & $-5,190960$ & Valor crítico a $1 \%$ * & $-4,0909$ \\
\hline & & Valor crítico a $5 \%$ & $-3,4730$ \\
\hline & & Valor crítico a $10 \%$ & $-3,1635$ \\
\hline
\end{tabular}

*Valores críticos de MacKinnon para a rejeição da hipótese de raiz unitária. 
Tabela A7: Teste de co-integração de Johansen para salário e produtividade do trabalho (1990-1994)

\section{Amostra: 1990:01 1994:06}

Observações incluídas: 49

Suposição do teste: presença de uma constante e tendência determinística linear nos dados Series: SALARIO PRODUTIV

Intervalo de defasagens: 1 to 8

\begin{tabular}{lcccr}
\hline Autovalor & $\begin{array}{c}\text { Razão de máxima } \\
\text { verossimilhança }\end{array}$ & $\begin{array}{c}\text { Valor crítico } \\
\text { a } 5 \%\end{array}$ & $\begin{array}{c}\text { Valor crítico } \\
\text { a } 1 \%\end{array}$ & Número hipotético de EC(s5) \\
\hline 0,394409 & 23,35169 & 15,41 & 20,04 & Nenhuma \\
\hline 0,017226 & 0,781915 & 3,76 & 6,65 & No máximo uma \\
\hline
\end{tabular}

O teste rejeita qualquer co-integração ao nível de significância de 5\%.

Tabela A8: Teste de co-integração de Johansen para salário e produtividade do trabalho (1994-2000)

Amostra: 1994:07 2000:12

Observações incluídas: 69

Suposição do teste: presença de uma constante e tendência determinística linear nos dados

Series: SALARIO PRODUTIV

Intervalo de defasagens: 1 to 8

\begin{tabular}{lcccr}
\hline Autovalor & $\begin{array}{c}\text { Razão de máxima } \\
\text { verossimilhança }\end{array}$ & $\begin{array}{c}\text { Valor crítico } \\
\text { a } 5 \%\end{array}$ & $\begin{array}{c}\text { Valor crítico } \\
\text { a } 1 \%\end{array}$ & Número hipotético de EC(s) \\
\hline 0,134871 & 15,75968 & 15,41 & 20.04 & Nenhuma* \\
\hline 0,080132 & 5,763214 & 3,76 & 6,65 & No máximo uma 1 \\
\hline
\end{tabular}

O teste rejeita qualquer co-integração ao nível de $5 \%$.

Tabela A9: Teste de co-integração de Johansen para salário e produtividade do trabalho (1990-2000)

Amostra: 1990:01 2000:12

Observações incluídas: 123

Suposição do teste: presença de uma constante e tendência determinística linear nos dados Series: SALARIO PRODUTIV

Lags: 1 to 8

\begin{tabular}{lcccr}
\hline Autovalor & $\begin{array}{c}\text { Razão de máxima } \\
\text { verossimilhança }\end{array}$ & $\begin{array}{c}\text { Valor crítico } \\
\text { a } 5 \%\end{array}$ & $\begin{array}{c}\text { Valor crítico } \\
\text { a } 1 \%\end{array}$ & Número hipotético de EC(s) \\
\hline 0.055834 & 9,089419 & 15,41 & 20,04 & None \\
\hline 0.016310 & 2,022707 & 3,76 & 6,65 & At most 1
\end{tabular}

O teste rejeita qualquer co-integração ao nível de $5 \%$.

Tabela A10: Teste de causalidade de Granger (1990-1994)

\begin{tabular}{lccc}
\hline Hipótese nula & Teste $\mathrm{F}$ & Probabilidade & Rejeição de $\mathrm{H}_{0}$ \\
\hline DPRODUTIV não causa DSALARIO & 1,57998 & 0,21695 & Não \\
\hline DSALARIO não causa DPRODUTIV & 3,45521 & 0,03999 & Sim \\
\hline
\end{tabular}


Tabela A11: Teste de causalidade de Granger (1994-2000)

\begin{tabular}{lccc}
\hline Hipótese nula & Teste $\mathrm{F}$ & Probabilidade & Rejeição de $\mathrm{H}_{0}$ \\
\hline DPRODUTIV não causa DSALARIO & 0,78150 & 0,46167 & Não \\
\hline DSALARIO não causa DPRODUTIV & 3,66307 & 0,03069 & Sim \\
\hline
\end{tabular}

Tabela A12: Teste de causalidade de Granger (1990-2000)

\begin{tabular}{lccc}
\hline Hipótese nula & Teste $\mathrm{F}$ & Probabilidade & Rejeição de $\mathrm{H}_{0}$ \\
\hline DPRODUTIV não causa DSALARIO & 1,57336 & 0,21146 & Não \\
\hline DSALARIO não causa DPRODUTIV & 2,55940 & 0,08143 & Sim \\
\hline
\end{tabular}

\section{NOTAS}

1. O IBGE utiliza horas pagas como uma proxy de horas trabalhadas; Sabóia e Carvalho (1997) apontam que, de um modo geral, essas duas variáveis têm a mesma evolução.

2. A fonte de dados para este cálculo são os dados do IBGE (PIM-PF e DG), refletindo o crescimento da produtividade da primeira metade da década apenas.

3. Ressalta-se novamente que o modelo de Ball e Moffit (2001) utilizado neste trabalho é útil uma vez que apresenta a relação entre a produtividade do trabalho e a variação de salário real.

4. Talvez até no limite entre aceitar/não aceitar $(p=0,0558)$. Entretanto, o software utilizado, Econometric Views 3.1, rejeita aço-integração.

5. Para testar a autocorrelação nos resíduos, foi utilizada a estatística do teste Breusch Godfrey. A hipótese nula deste teste é a de que os coeficientes dos resíduos da regressão são zero. Tal hipótese não pôde ser rejeitada $(p=0,36$ e $p=0,26)$ para as regressões 1 (sem a variável desemprego defasada) e 2 (com o desemprego defasado em dois períodos).

\section{REFERÊNCIAS BIBLIOGRÁFICAS}

ALMEIDA, E. S. (1999) "Mudança institucional e estrutural na economia brasileira do início dos anos 90”. Revista Análise Econômica, ano 17, n. 31, São Paulo.

BALL, L., MOFFIT, R. (2001) Productivity growth and the Phillips Curve. Johns Hopkins University.

BARROS, J. R. M., GOLDENSTEIN, L. (1997) “Avaliação do processo de reestruturação industrial brasileiro”. Revista de Economia Política, v. 17, n. 66, São Paulo.

BONELLI, R., FONSECA, R. (1998) “Produtividade, salários e emprego na indústria brasileira: uma avaliação da evolução recente”. Notas sobre o mercado de trabalho, n. 3.

(1999) “A reestruturação industrial brasileira nos anos 90: reação empresarial e mercado de trabalho". In: A. C. Posthuma (org.), Abertura e ajuste do mercado de trabalho no Brasil: politicas para conciliar os desafios de emprego e competitividade. Brasília: OIT e TEM. 
CAMARGO, J. M., NERI, M., REIS, M. C. (1999) "Emprego e produtividade no Brasil na década de noventa”. Textos para discussão n. 405. Rio de Janeiro: IPEA.

CARVALHO, P. G. M. (2000) “As causas do aumento da produtividade da indústria brasileira nos anos 90". Tese de doutoramento. Rio de Janeiro: UFRJ/IE.

CASTRO, A. B. (1999) “Indústria: o crescimento fácil e a inflexão possível”. In: J. P. R. Velloso, A crise mundial e a nova agenda de crescimento. XI Fórum Nacional. Rio de Janeiro: José Olympio.

CONSIDERA, C. M. (1995) “Ideologia, globalização e emprego". Jornal do Economista, n. 83, Corecon.

COUTINHO, L. (1997) “A especialização regressiva: um balanço do desempenho industrial pós-estabilização”. In: J. P. R. Velloso (coord.), Brasil: desafios de um país em transformação. Rio de Janeiro: José Olympio.

FEIJÓ, C., CARVALHO, P. G. (1994) "Sete teses equivocadas sobre o aumento da produtividade industrial nos anos recentes”. Boletim de Conjuntura. Rio de Janeiro: IEI/UFRJ.

FRANCO, G. H. B. (1998) “A inserção externa e o desenvolvimento”. Revista de Economia Política, v. 18, n. 3, São Paulo.

GUjARATI, D. N. (2000) Econometria básica. São Paulo: Makron Books.

IBGE. Instituo Brasileiro de Geografia e Estatística. www.ibge.org.br.

RAMOS, L., REIS, J. G. A. (1997) “Emprego no Brasil: os anos 90”. In: J. P. R. Velloso (coord.), Brasil: desafios de um país em transformação. Rio de Janeiro: José Olympio.

ROSSI JR., J. L., FERREIRA, P. C. (1999) “A evolução da produtividade industrial brasileira e abertura comercial”. Textos para discussão. Rio de Janeiro: IPEA.

SABÓIA, J., CARVALHO, P. G. M. (1997) "Produtividade na indústria brasileira: questões metodológicas e análise empírica”. Texto para discussão. Rio de Janeiro: IPEA.

SILVA, A. O., DOELLINGER, C., CONSIDERA, HORTA, M. H., LEVY, P. M., VILLELA, R. (1993) "Retrospectiva da economia brasileira". Perspectivas da Economia Brasileira - 1994. Rio de Janeiro: IPEA. 